\section{Three-dimensional Quantitative Porosity Characterization of Syringe- versus Hand-mixed Set Epoxy Resin Root Canal Sealer}

Gustavo De-Deus ${ }^{1}$, Miriam Z. Scelza1, Prasanna Neelakantan², Subash Sharma ${ }^{2}$, Aline de Almeida Neves ${ }^{3}$, Emmanuel João Nogueira Leal Silva ${ }^{4}$

\author{
'Department of Endodontics, \\ UFF - Universidade Federal \\ Fluminense, Niterói, RJ, Brazil \\ ${ }^{2}$ Conservative Dentistry and \\ Endodontics Department, Saveetha \\ University, Chennai, Temil Nadu, India \\ ${ }^{3}$ Department of Pediatric Dentistry, \\ UFRJ - Federal University of Rio de \\ Janeiro, Rio de Janeiro, RJ, Brazil \\ ${ }^{4}$ Department of Endodontics, \\ UNIGRANRIO - Grande Rio University, \\ Duque de Caxias, RJ, Brazil
}

Correspondence: Dr. Emmanuel João Nogueira Leal Silva, Rua Erotides de Oliveira 61/902, Icaraí, 24230-230 Niterói, RJ, Brasil. Tel:+55-21-2610-8439 e-mail: nogueiraemmanuel@hotmail.com

Jet $^{\mathrm{tw}}$ syringe-mix and the conventional hand-mixed AH Plus root canal sealers by threedimensional quantitative high-resolution micro-computed tomography (micro-CT). Seven test specimens were prepared from each tested sealer by a single operator following the manufacturer's instructions and poured into pre-lubricated plastic split-ring moulds. Set sealer test specimens were scanned using a micro-CT device and the shadow images were reconstructed into cross-sectional slices. The evaluated parameters were (i) total pore count, (ii) total pore volume and mean pore volume, (iii) total porosity (\% of pore volume in relation to total sealer volume) and (iv) mean pore distance to the sealer lateral external surface. In both groups, most pores were localized within the external sealer perimeter ( $0.05 \mathrm{~mm}$ from the external surface). Hand-mixed AH Plus specimens showed statistically significant higher mean total pore count, total pore volume and total porosity $(p=0.001)$ than the syringe-mixed specimens. However, mean pore sizes in $\mathrm{AH}$ Plus syringe-mixed specimens were significantly higher $(p=0.046)$ than the AH Plus hand-mixed counterparts. Hand-mixed AH Plus was associated with higher total mean pore count, volume and total porosity compared to syringe mixed AH Plus.

Key Words: epoxy resin
sealer, hand-mix, micro-CT,
porosity, syringe-mix.

\section{Introduction}

Root canal sealers are interfacial materials for sealing the space between the dentinal wall and the filling core material. This means that they serve to fill voids and irregularities within the root canal system as well as the space between gutta-percha-based obturation techniques (1). Currently, root canal sealers are regarded as a pivotal component for root canal filling procedures, based on the premise that root fillings are expected to gradually leak over time in the absence of an adequate sealer $(2,3)$.

For this reason, much effort in endodontic research has been devoted towards the development of root canal sealers with improved physical and biological properties. In fact, it is already known that sealer disintegration can play a role in the long-term outcome failure of endodontic fillings by creating leakage channels, allowing periradicular tissue fluids to reach residual intratubular bacteria and provide nutrients for their development (4). Moreover, it has also been shown that solubility is closely related to the porosity of a root canal sealer (5).

The process of pore formation within root canal sealers can be regarded as a result of the interplay between its physical properties and mixing/manipulation process itself. Hand-mixed materials appear to be more prone to subjective operator-induced factors, resulting in more structural defects (pores) (6). To minimize these problems, automatic proportioning and mixing procedures have been incorporated into commercially available materials, resulting in a better balanced ratio of sealer components, reproducible mixing process and improved sealer physicomechanical properties (7). Experimental analysis of root canal sealers should thus include their microstructural characterization $(8,9)$.

AH Plus (Dentsply De Trey) is an epoxy-resin based material with good sealing ability, low solubility and relatively short setting time $(10,11)$. Moreover, it sets in the presence of moisture and has high tissue compatibility (12), being considered as the "gold-standard" endodontic sealer. AH Plus Jet ${ }^{\text {TM }}$ (Dentsply De Trey) is provided in auto-mixing syringes with disposable tips, ensuring a homogeneous and balanced mixing of components (13).

The present study was designed to compare the porosity characteristics of AH Plus Jet'" syringe-mix and conventional hand-mixed AH Plus root canal sealers by means of threedimensional quantitative high-resolution micro-computed tomography (micro-CT). The tested null hypothesis was that there is no significant difference in the porosity pattern between syringe- and hand-mixed set AH Plus sealer.

\section{Material and Methods}

Sample Preparation

This laboratory-based study was performed following 
the ISO 6876/86 regulations (14). Seven cylindrical test specimens of the AH Plus and AH Plus Jet"' root canal sealers were produced using plastic split ring moulds with $4.0 \pm 0.1$ $\mathrm{mm}$ height and $7.0 \pm 0.1 \mathrm{~mm}$ diameter. A single operator prepared all test specimens following the manufacturer's guidelines regarding proportion and manipulation (Table 1).

The internal surfaces of the ring moulds were lubricated and laid over a glass slab. Conventional hand-mixed AH Plus sealer, removed from all parts of the sealer tube, was poured into the moulds by a metallic spatula placed vertically in the centre of the mould. By touching the glass slabs, the spatula-driven sealer was allowed to flow down and fill the mould by gravitation with no further vibration or pressure applied on the material. The syringe-mixed sealer AH Plus Jet ${ }^{\text {tw }}$ was inserted into the moulds using the auto-mix syringe provided by the manufacturer. After a slight overfill, a methacrylate film was placed over the rings and firmly held together with the glass slabs using a clamp. The apparatus was kept at $100 \%$ humidity in a $37^{\circ} \mathrm{C}$ furnace for 7 days to allow complete setting of the sealers.

\section{Micro-CT Acquisition and Reconstruction}

The specimens were scanned using a highresolution desktop micro-CT device (SkyScan 1173; Bruker micro-CT, Kontich, Belgium) using the following parameters: $130 \mathrm{kV}, 61 \mu \mathrm{A}, 5.66 \mu \mathrm{m}$ resolution, $1800 \mathrm{~ms}$ exposure, $0.5^{\circ}$ rotation step and a $1 \mathrm{~mm}$-thick aluminium (Al) filter. Frame averaging of 5 and random movements of 100 with $360^{\circ}$ rotation were also used.

Reconstruction of the shadow projections into grayscale cross-sectional slices was performed with the SkyScan proprietary software interface (NRecon v.1.6.4; Bruker micro-CT). The reconstruction parameters included 100\% beam hardening correction (corresponding to a second order polynomial correction), ring artefact correction of 10 and setting of standardized minimum and maximum contrast levels (0-0.3).

\section{Image Processing and Analysis}

Even with the use of a physical $1 \mathrm{~mm}$-thick Al filter and software correction for beam hardening artefacts, the grey values were not homogeneously distributed along the whole sample thickness (Fig. 1A,B) with some slices presenting a more radiopaque centre. To overcome this problem, instead of a simple segmentation algorithm, a fast Fourier transform plugin filter, implemented in the opensource ImageJ/FIJI software (15) was used, implemented in
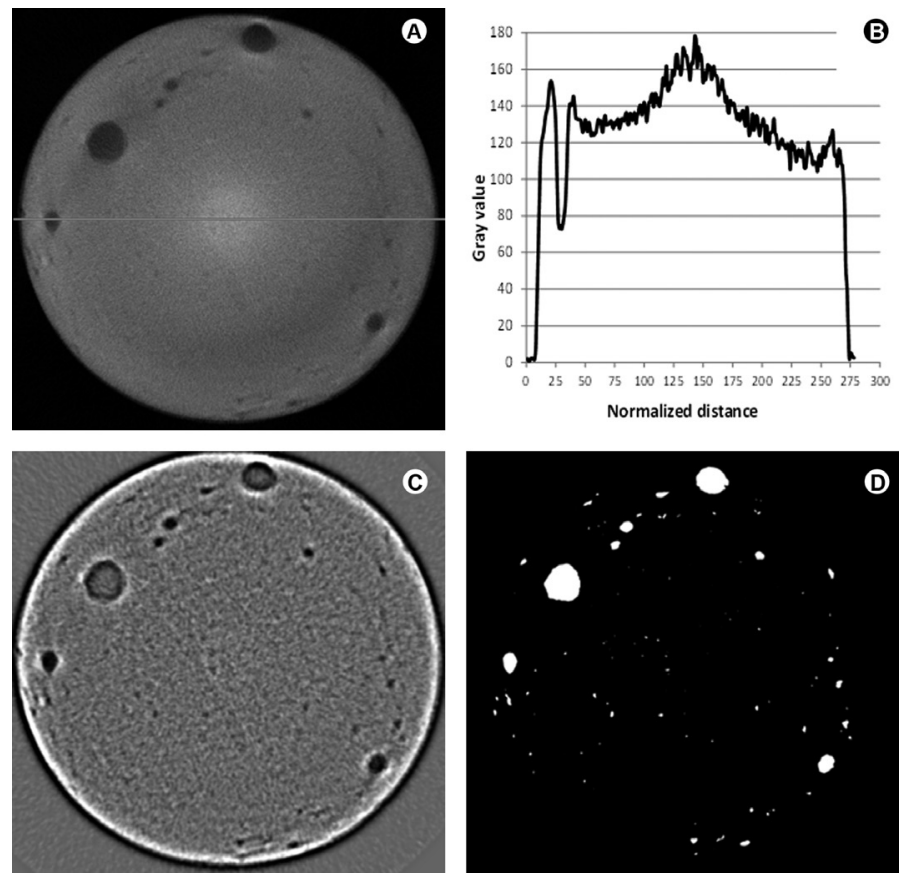

Figure 1. A: Reconstructed cross-section slice from one sealer specimen. B: Gray value distributions along a path (horizontal line, 1A). C: Cross sectional image after FFT filtering. D: Pore segmentation results after Otsu-based threshold.

Table 1. Materials, composition and application directions followed in the present study

\begin{tabular}{|c|c|c|c|}
\hline Material & Sealer preparation & Composition & Manufacturer \\
\hline AH Plus & $\begin{array}{l}\text { Mix equal volume units }(1: 1) \text { of Paste } A \text { and } \\
\text { Paste B on a glass slab or a mixing pad using a } \\
\text { metal spatula to a homogeneous consistency }\end{array}$ & $\begin{array}{l}\text { Paste A: bisfenol-A epoxy resin, bisfenol-F } \\
\text { epoxy resin, calcium tungstate, zirconium } \\
\text { oxide, silica, iron oxide pigments } \\
\text { Paste B: dibenzyldiamine, aminoadamantane, } \\
\text { tricyclodecane-diamide, calcium tungstate, } \\
\text { zirconium oxide, silica, silicone oil }\end{array}$ & $\begin{array}{l}\text { Dentsply De Trey } \\
\text { GmbH, Konstanz, } \\
\text { Germany }\end{array}$ \\
\hline $\begin{array}{l}\text { AH Plus } \\
\text { Jet }^{\mathrm{Tm}}\end{array}$ & $\begin{array}{l}\text { Auto-mixing syringe for direct intra-oral application. } \\
\text { 1. Remove the cap by turning it } 90^{\circ} \text { counter- } \\
\text { clockwise and pulling it. To ensure appropriate } \\
\text { mixing, bleed the syringe prior to the first use; } 2 \text {. } \\
\text { Attach the mixing tip to the syringe, aligning the } \\
\text { notch; } 3 \text {. Turn the tip } 90^{\circ} \text { clockwise and secure } \\
\text { the mixing tip in place; } 4 \text {. Apply the sealer }\end{array}$ & $\begin{array}{l}\text { Paste A: bisfenol-A epoxy resin, bisfenol-F } \\
\text { epoxy resin, calcium tungstate, zirconium } \\
\text { oxide, silica, iron oxide pigments } \\
\text { Paste B: dibenzyldiamine, aminoadamantane, } \\
\text { tricyclodecane-diamide, calcium tungstate, } \\
\text { zirconium oxide, silica, silicone oil }\end{array}$ & $\begin{array}{l}\text { Dentsply De Trey } \\
\text { GmbH, Konstanz, } \\
\text { Germany }\end{array}$ \\
\hline
\end{tabular}


the open-source ImageJ/FIJI software (16) (Fig. 1C). Using this filter, large structures (shading correction) and small structures (smoothing) are corrected by a Gaussian filter applied in the Fourier space.

After filtering, an automatic Otsu-based segmentation algorithm was used (17) to produce a binary image of the three-dimensional (3D) pore structure (Fig. 1D).

\section{Quantitative Analysis and 3D Renderings}

Quantitative results were obtained by means of the "3D object counter" plugin implemented in the ImageJ/ FIJI interface (18) after calibration of the used resolution. The evaluated Parameters included: total pore count, total pore volume, mean pore volume, total porosity ( $\%$ of pore volume in relation to total sealer volume) and mean pore distance to the sealer lateral external surface.

A 3D volumetric rendering of one illustrative specimen from each group was performed using the 3D Viewer plugin (19).

\section{Statistical Analysis}

Preliminary analysis of the raw pooled data did not show Gaussian distribution (D'Agostino \&t Person omnibus

Table 2. Quantitative porosity data obtained from sealer samples according to the mixing procedures

\begin{tabular}{lcccc}
\hline Group $(\mathrm{n}=7)$ & $\begin{array}{c}\text { Mean total } \\
\text { pore count }\end{array}$ & $\begin{array}{c}\text { Mean total pore } \\
\text { volume }\left(\mathrm{mm}^{3}\right)\end{array}$ & $\begin{array}{c}\text { Mean pore } \\
\text { volume }\left(\mathrm{mm}^{3}\right)\end{array}$ & $\begin{array}{c}\text { Total } \\
\text { porosity }(\%)\end{array}$ \\
\hline $\begin{array}{l}\text { AH Plus } \\
\text { (hand-mixed) }\end{array}$ & $3111 \pm 808^{\mathrm{a}}$ & $3.67 \pm .90^{\mathrm{a}}$ & $0.0012 \pm 0.0002^{\mathrm{a}}$ & $2.22 \pm 0.54^{\mathrm{a}}$ \\
$\begin{array}{l}\text { AH Plus Jet } \\
\text { (syringe-mixed) }\end{array}$ & $43 \pm 37^{\mathrm{b}}$ & $0.15 \pm 0.14^{\mathrm{b}}$ & $0.0039 \pm 0.0023^{\mathrm{b}}$ & $0.09 \pm 0.08^{\mathrm{b}}$ \\
\hline
\end{tabular}

Different letters indicate statistically significant difference between the groups for the same parameter $(\mathrm{p}<0.05)$. normality test); thus, Mann-Whitney tests were used to assess the size effect of each tested parameter. The level of significance was set at 5\% and SPSS 11.0 (SPSS Inc., Chicago, IL, USA) was used as the statistical tool.

Cohen's effect size was calculated for each statistical comparison using the formula:

$$
\frac{\tilde{X}_{1}-\tilde{X}_{2}}{0.75\left(Q_{3}-Q_{1}\right)}
$$

where: $\tilde{X}_{1}-\tilde{X}_{2}$ is the difference between median values in each group and $Q_{3}-Q_{1}$ is the difference between the pooled third and first quartile. The effect size was calculated in order to access the magnitude of each statistically significant result. Effect size values higher than 0.8 indicate high strength of statistical significance.

\section{Results}

Table 2 shows quantitative porosity results for both tested sealers. Hand-mixed AH Plus specimens showed statistically significant higher mean total pore count, total pore volume and total porosity ( $p=0.001$; Mann-Whitney test) than AH Plus Jet" specimens. However, mean pore size in AH Plus syringe-mixed specimens were statistically higher $(p=0.046)$ than AH Plus hand-mixed counterparts. All statistical results resulted in effect size values higher than 0.8 , indicating high significance power.

Figure $2 \mathrm{~A}$ shows percentage of pores according to different pore volume classes in each sample for both tested sealers. It may be observed that for both materials, most pores were around $0.001 \mathrm{~mm}^{3}$. Figure $2 \mathrm{~B}$ shows distribution of pore distance to the sealer lateral external surface for each sample and
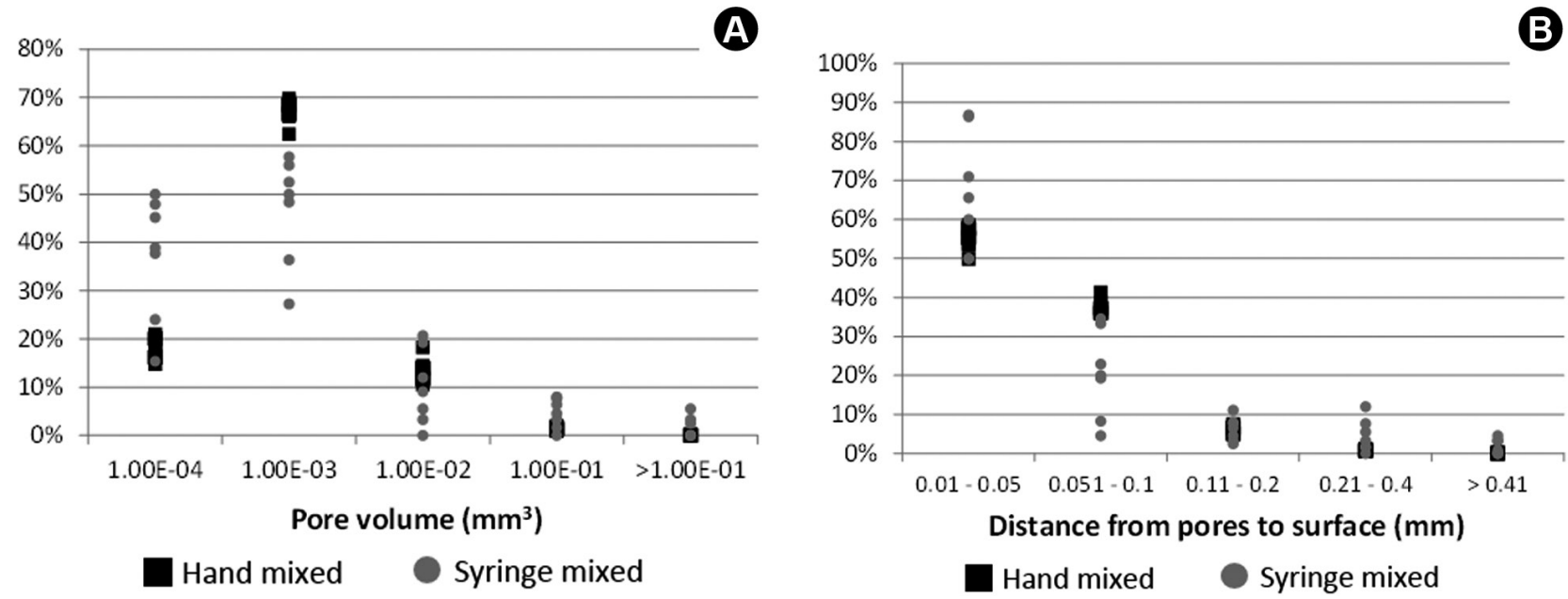

Figure 2. A: Percentage of pores according to the different pore volume classes for both mixing methods. B: Percentage of pores according to the distance to the sealer lateral external surface for both mixing procedures. 
tested sealers, where the majority of pores were localized within the external sealer perimeter $0.05 \mathrm{~mm}$ from the external surface). Figures $3 \mathrm{~A}$ and $3 \mathrm{~B}$ show $3 \mathrm{D}$ renderings of one representative sample for each tested sealer material.

\section{Discussion}

One of the most important requirements of root canal sealers is that they be insoluble or at least possess minimal solubility. This stems from the biological rationale that any component leaching into the periradicular tissues owing to solubility of the sealer could exert toxic effects on the tissues. Furthermore, a high porosity sealer is expected to exhibit poor sealability, allowing periradicular tissue fluids to penetrate into the root canal space, supporting microbial metabolism, which may jeopardize the root canal treatment (5). There are basically three routes of leakage: material-tooth interface, core material-sealer interface and within the material. From the several factors that influence the solubility behaviour of a set material, porosity is an important parameter (19).

According to the obtained results, hand-mixed AH Plus showed 2.22\% total porosity, while AH Plus syringe-mixed showed $0.09 \%$ total porosity. These values were statistically

sealers displayed significantly higher surface porosity than the syringe-mixed ones as observed in scanning electron microscopy (20). Regarding repair cements, a micro-CT study showed total mean porosity values varying from 5.91 to $9.58 \%$ for calcium silicate-based repair cements (8). In the present study, mean pore volume was higher for the syringe-mix AH Plus Jet ${ }^{\text {tw }}$ compared to the conventional hand-mixed AH Plus ( $p=0.046)$ and this finding may be due to differences in the mixing process between the two commercial products as their chemical formulation is the same. A recent study showed great variability in
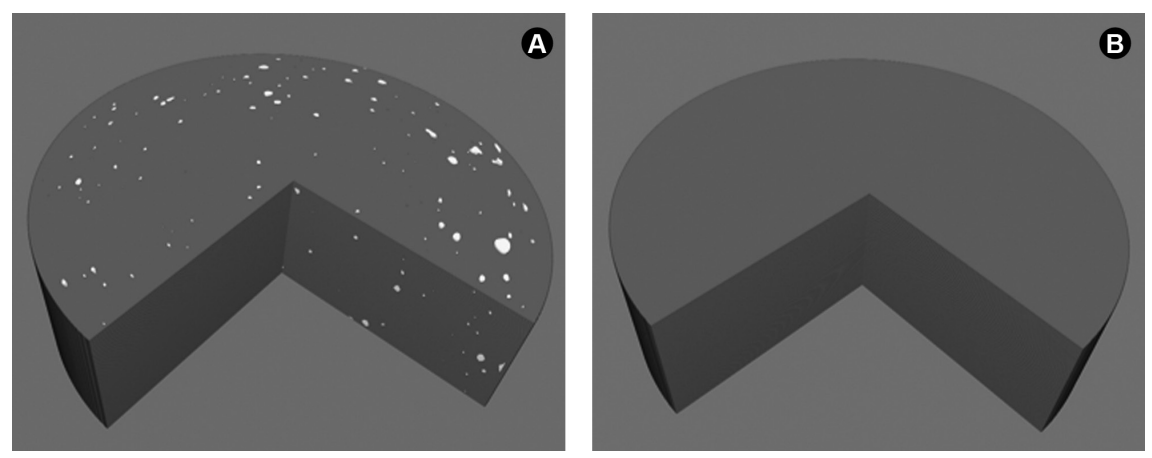

Figure 3. A: 3D rendering of a representative sample from the AH Plus group. B: 3D rendering of a representative sample from $\mathrm{AH}$ Plus Jet ${ }^{\mathrm{nt}}$ group. Cut shows internal porosity. the physicochemical properties of samples taken from the different parts of the same tube of hand-mixed AH Plus (21) and this result highlights the potential mixing problems with hand-mixed sealers. The possibility of physicochemical differences could also explain the differences in the distance from pores to surface as shown in Figure 1. If the sealer mixture is dense and barely flows, only few bubbles will move and open up at the surface. Conversely, if the mixture is fluid, the bubbles will burst open easier on the surface (5). It is thus reasonable to assume that the differences observed among the mixing approaches could be related to this phenomenon.

AH Plus Jet ${ }^{\text {tm }}$ syringe-mix comes in a double-barrel syringe, which is able to provide a quicker and cleaner mixing process. The disposable mixing tip automatically mixes the sealer components in the ideal ratio, which may have some impact on its porosity pattern. Moreover, syringe mixing may help discard susceptibility to operator-induced variability $(5,21,22)$, resulting in a sealer with optimal final physical properties, as determined by the manufacturer.

In the present study, the sealers were inserted into the plastic molds and allowed to flow down by gravitation with no further vibration or pressure applied $(5,20,23)$. It is important to emphasize that the results provided by this methodology are comparative but should not be directly extrapolated to the clinical situation, because the usual sealer insertion techniques involve the use of guttapercha, paper points or lentulo spirals, which may alter both the internal and surface porosity of the sealers (24). Moreover, some filling techniques might also increase the porosity of endodontic sealers, owing to incorporation of air during the procedures. Therefore, future studies should investigate air bubbles at the interface with the use of gutta-percha points, leading to the recommendation of certain techniques that would potentially promote fewer and/or smaller air bubbles.

Under the conditions of the present study, it can be concluded that hand-mixed AH Plus sealer was associated with higher total mean pore count, volume and total porosity compared to syringe-mixed counterpart. Further studies are required to evaluate the physico-chemical properties of hand- and syringe-mixed endodontic sealers. Furthermore, laboratory models simulating the effect of the different mixing processes on the filling techniques should be used to produce a better understanding and clinical extrapolation of the results observed in the present 
study.

\section{Resumo}

0 objetivo do presente estudo foi comparar a porosidade do AH Plus Jet $^{\text {tw }}$ dotado de misturador automático com o AH Plus convencional manipulado a mão a partir de um método quantitativo de microtomografia computadorizada (micro-CT). Para cada cimento, sete espécimes foram preparados por um único operador, seguindo as instruções do fabricante, $e$ inseridas em anéis de plástico. Após o tempo de presa, os cimentos foram escaneados utilizando o micro-CT e as imagens foram reconstruídas. Os parâmetros avaliados foram (i) contagem total de poros, (ii) volume total de poros e média dos volumes dos poros, (iii) porosidade total (\% de volume de poros em relação ao volume total do cimento) e (iv) distância média dos poros em relação ao perimetro externo $(0,05 \mathrm{~mm}$ da superfície externa). 0 AH Plus manipulado a mão apresentou maior número de poros, maior volume total de poros e porosidade total $(p=0,001)$ comparado com o AH Plus com misturador. No entanto, a média de tamanho dos poros foi estatisticamente superior no AH Plus com misturador quando comparado com o AH Plus manipulado a mão $(p=0,046)$. 0 AH Plus manipulado a mão foi associado com uma maior média de poros, volume e porosidade quando comparado com o AH Plus com misturador.

\section{Acknowledgements}

The authors deny any conflict of interest. This study was partially funded by FAPERJ grants E-26/102.169/2013, E-26/201.491/2014 and E-26/111.690/2013.

\section{References}

1. Li GH, Niu LN, Zhang W, Olsen M, De-Deus G, Eid AA, et al.. Ability of new obturation materials to improve the seal of the root canal system: a review. Acta Biomater 2014;10:1050-1063.

2. Kontakiotis EG, Wu MK, Wesselink PR. Effect of sealer thickness on long-term sealing ability: a 2-year follow-up study. Int Endod J 1997; 30:307-312.

3. Wu MK, Fan B, Wesselink PR. Diminished leakage along root canals filled with gutta-percha without sealer over time: a laboratory study. Int Endod J 2000;33:121-125.

4. Siqueira JF Jr. Aetiology of root canal treatment failure: why welltreated teeth can fail. Int Endod J 2001;34:1-10.

5. Mutal L, Gani 0. Presence of pores and vacuoles in set endodontic sealers. Int Endod J 2005;38:690-696.

6. Mitchell CA, Douglas WH. Comparison of the porosity of handmixed and capsulated glass-ionomer luting cements. Biomaterials 1997;18:1127-1131.

7. Akhavan H, Zahdabadi F, Mehrvarzfar $\mathrm{P}$, Birjandi A. Comparative study on the microleakage of three root canal sealers. Iranian Endod J
$2011 ; 6: 1-5$.

8. De Souza ET, Nunes Tameirão MD, Roter JM, De Assis JT, De Almeida Neves A, De-Deus GA. Three-dimensional quantitative porosity characterization of three set calcium silicate-based repair cements for endodontic use. Microsc Res Tech 2013;76:1093-1098.

9. Mokeem-Saleh A, Hammad M, Silikas N, Qualthrough A, Watts DC. A laboratory evaluation of physical and mechanical properties of selected root canal sealers. Int Endod J 2010;43:882-888.

10. Pommel L, About I, Pashley D, Camps J. Apical leakage of four endodontic sealers. J Endod 2003;29:208-210.

11. Silva EJ, Rosa RP, Herrera DR, Jacinto RC, Gomes BP, Zaia AA. Evaluation of cytotoxicity and physicochemical properties of calcium silicatebased endodontic sealer MTA Fillapex. J Endod 2013;39:274-277.

12. Gomes-Filho JE, Gomes BP, Zaia AA, Ferraz CR, Souza-Filho FJ. Evaluation of the biocompatibility of root canal sealers using subcutaneous implants. J Appl Oral Sci 2007;15:186-194.

13. Mahajan VA, Kamra Al. An in vitro evaluation of apical sealing of three epoxy resin-based commercial preparations. Endodontology 2007;19:7-11.

14. ISO-6876. Dental Root Canal Sealing Materials. Geneva, Switzerland: International Organization for Standardization; 2001.

15. Walter J. FFT filter. http://rsb.info.nih.gov/ij/plugins/fft-filter.html, 2007.

16. Schneider CA, Rasband WS, Eliceiri KW. NIH image to ImageJ: 25 years of image analysis. Nat Methods 2012;9:671-675.

17. Otsu N. A threshold selection method from gray-level histograms. IEEE Transactions on Systems, Man and Cybernetics 1979;9:62-66.

18. Cordelires $F_{1}$ Jackson J. 3D object counter. Available from: http:// rsbweb.nih.gov/ij/plugins/track/objects.html. Latest access.

19. Klose D, Siepmann F, Elkharraz K, Krenzil S, Siepmann J. How porosity and size affect the drug release mechanisms from PLGA-based microparticles. Int J Pharm 2006;18:198-206.

20. Uyanik MO, Nagas E, Cubukcu HE, Dagli F, Cehreli ZC. Surface porosity of hand-mixed, syringe-mixed and encapsulated set endodontic sealers. Oral Surg Oral Med Oral Pathol Oral Radiol Endod 2010;109:117-122.

21. Baldi JV, Bernardes RA, Duarte MA, Ordinola-Zapata R, Cavenago BC, Moraes JC, et al.. Variability of physicochemical properties of and epoxy resin sealer taken from different parts of the same tube. Int Endod $J$ 2012;45:915-920.

22. McElroy DL. Physical properties of root canal filing materials. J Am Dent Assoc 1955;50:433-440.

23. Gandolfi MG, Siboni $F$, Primus $C M$, Prati C. Ion release, porosity, solubility, and bioactivity of MTA Plus tricalcium silicate. J Endod 2014:40:1632-1637.

24. Guinesi AS, Faria G, Tanomaru-Filho M, Bonetti-Filho I. Influence of sealer placement technique on the quality of root canal filling by lateral compaction or single cone. Braz Dent J 2014;25:117-122.

Received February 9, 2015

Accepted September 11, 205 